\title{
Endogenous free riding and the decentralized user-fee financing of spillover goods in a $n$-region economy
}

\author{
Clemens Fuest • Martin Kolmar
}

Published online: 28 March 2012

(C) Springer Science+Business Media, LLC 2012

\begin{abstract}
The paper analyzes the strategic effects of decentralized user-fee and enforcement policies for the financing of interregional spillover goods. We derive the equilibrium pricing and enforcement rules for a $n$-region economy. We show that under mild conditions on the pattern of substitution between spillover goods and contrary to the 2-region case, the decentralized equilibrium cannot be Pareto improved by coordinated policy changes. However, decentralized equilibria are suboptimal from the point of view of utilitarian welfare. We characterize the direction of the distortion for this case. The regions' incentives for user-fee enforcement are ambiguous in general. With only two regions and if regions only charge non-residents, however, there is overinvestment in user-fee enforcement in the decentralized equilibrium. For the case of a Tullock enforcement function and linear demand for the spillover goods we show that welfare is $\mathrm{u}$-shaped in a parameter that measures the technological advantage of user-fee enforcement.
\end{abstract}

Keywords Public goods $\cdot$ Club goods $\cdot$ Contests $\cdot$ Fiscal federalism

JEL Classification D74 $\cdot \mathrm{H} 41 \cdot \mathrm{H} 70 \cdot \mathrm{K} 42$

\section{Introduction}

The literature on fiscal decentralization focuses on the potential advantages and disadvantages of decentralized responsibilities for the provision of publicly provided

C. Fuest

Saïd Business School, University of Oxford, Park End Street, Oxford OX1 1HP, UK

M. Kolmar $(\bowtie)$

Institute of Economics, University of St. Gallen, Varnbüelstrasse 19, 9000 St. Gallen, Switzerland e-mail: martin.kolmar@unisg.ch 
goods. ${ }^{1}$ Tiebout-type models (Tiebout 1956) stress that the decentralized provision of local public goods may be superior to centralized provision if the central agency is constrained in the choice of instruments and voter-citizens are sufficiently mobile to vote by feet. In a democracy, individuals with heterogeneous preferences may have to accept compromises in the supply of public goods that may be overcome if they sort according to preferences. This positive effect of decentralization depends on the assumption, among others, that the goods provided by the regional authorities do not create spillovers to other regions. Existing spillovers may prohibit the efficiency of a decentralized solution even if individuals are perfectly sorted according to preferences. One way to internalize these potential externalities is to create a system of interregional transfer payments. For a number of spillover goods, an alternative is to charge resident and non-resident users a price for the use of regional spillover goods (Fuest and Kolmar 2007). Two important aspects of user fees are the costs of running these systems and the possibilities to discriminate prices with respect to user groups.

Similar to the case of tax compliance, rational individuals will try to find ways to circumvent the payment of user fees. Therefore, the enforcement of user fees is an economic activity where governments trade off benefits and costs. A prominent example is the enforcement of road tolls. For example, Germany raises fees for the use of the highway system by commercial trucks. The charge per kilometer varies according to the number of axles and the vehicle's emission category and ranges between 9 and 14 cents per kilometer. This means that the fee for e.g. a HamburgMunich trip (776 km) is between 69.84 and 108.64 Euros. Annual gross revenue was 3.4 billion Euros in 2007. The cost of operating the toll system is considerable and amounts to an estimated $20 \%$ of gross revenues. This number underestimates the total costs of the system because it abstracts from the huge development and setup costs. The system has a high degree of accuracy, estimated at $98 \%$. According to this estimate, the technology employed to enforce the payment of user fees almost completely prevents free riding, but the operative costs are substantial. ${ }^{2}$ There is a current discussion to extend the system to non-commercial vehicles ${ }^{3}$ and roads other than highways. ${ }^{4}$

Road tolls are a good example for the use of user fees with substantial enforcement costs. The opposite is probably true for the case of higher education where enforcing compliance is relatively easy. In addition, price discrimination is frequently observed. In the USA, tuition costs vary from $\$ 5000$ to $\$ 30000$ per year. About $\$ 9000$ for resident students and $\$ 20000$ for international students. Canadian universities charge around \$9000 for domestic and \$25 500 for international students. In Europe, several countries have been considering reforming higher education and moving towards a system that charges users. ${ }^{5}$ In UK, the maximum tuition fee amount that can

\footnotetext{
${ }^{1}$ See Oates (1999) for a comprehensive survey of the literature.

${ }^{2}$ See the official homepage of the ministry, http://www.bmvbs.de/Verkehr/-, 1430/Strasse.htm, for further information.

${ }^{3}$ http://www.sueddeutsche.de/X5q382/4053084/Koalition-uneins-ueber-Pkw-Maut.html.

${ }^{4}$ http://www.faz.net/s/Rub0E9EEF84AC1E4A389A8DC6C23161FE44/Doc ED9945D97BF70466B95337AB1485506DB ATpl Ecommon Scontent.html.

${ }^{5} \mathrm{~A}$ comparison can be found at http://www.studyineurope.eu/tuition-fees.
} 
be charged to EU students is $£ 3145$ a year. Average tuition for domestic students is around $£ 3000$, and for international students about $£ 10000$ a year. ${ }^{6}$ There is a current debate about a sharp increase in tuition fees in the future. ${ }^{7}$ According to the rector's conference of Swiss universities, 5 out of 12 universities charge higher tuition fees for foreigners, ranging from CHF 200 per annum at the University of Zurich to CHF 4000 at the Universita della Svizzera Italiana. ${ }^{8}$

The costs to enforce compliance seem to be relatively small compared to, for example, road pricing, but they are, without doubt, larger than zero. For example the establishment of procedures that become necessary to administer the fees is part of the enforcement costs. This is also true for other examples of user-fee financing like e.g. local and interregional public transport. More importantly, if investments follow the usual marginal costs-marginal benefits logic, even small enforcement costs lead to distortions elsewhere. In this paper we interpret the enforcement costs of user fees as an equilibrium outcome where individual users invest resources to circumvent the payment of user fees and the regional authorities invest resources to enforce them. Different equilibrium levels of investment reflect different, good-specific technologies of enforcement. We therefore interpret the different patterns observed for the different goods and services (e.g. road pricing and university education) as rational outcomes for different enforcement technologies.

This paper builds on earlier work by Fuest and Kolmar (2007) who have explored the strategic incentives to set user fees if two regions provide non-rival goods. A major finding of their paper is that user fees can be either inefficiently low or inefficiently high, depending on whether the spillover goods are substitutes or complements. Their analysis, however, is restricted to two regions and perfect and costless enforceability of user fees. It turns out that under a mild condition their results do not readily carry over to the $n$-region case. If all spillover goods are either substitutes or complements to each other, the 2-region case is representative for the $n$-region case, but as soon as some spillover goods are complements and some are substitutes, there is no room for Pareto-improving policy coordination. It can, however, be shown that in these mixed cases the decentralized equilibrium is suboptimal from the point of view of utilitarian welfare. If one is willing to apply this criterion, a measure of average substitutability determines whether user fees are suboptimally high or low.

Whether or not spillover goods are all substitutes or complements depends on the good or service at hand. It can be argued that education services offered by universities in different regions are substitutes. However, the pattern of substitutability between roads depends crucially on geographic peculiarities. If, for example, a haulage company wants to ship freight from the port of Rotterdam in the Netherlands to Basel at the Swiss-German-French border, it has to use the Dutch road system but has the choice between continuing via France or Germany.

As a novel aspect of this paper, we analyze the enforcement of user fees as an economic activity. Contrary to standard models that either assume that exclusion is

\footnotetext{
${ }^{6}$ http://education.guardian.co.uk/students/internationalstudents/page/0,,1941450,00.html.

${ }^{7}$ http://www.guardian.co.uk/education/2011/feb/06/univerisites-fee-charge-students.

${ }^{8}$ http://www.crus.ch/information-programme/studieren-in-der-schweiz.html\#8_Kosten.
} 
impossible and the market mechanism cannot be applied (public goods), or that exclusion is possible and does not create economic costs (club goods), exclusion is the result of an investment decision that can be analyzed using standard opportunitycosts arguments. Surprisingly there are very few articles that explicitly analyze the production process and the associated costs of exclusion. ${ }^{9}$ One exception from this observation is the growing literatures on law enforcement (see Polinsky and Shavell 2000 for a survey) and on anarchy and conflict. ${ }^{10}$ We borrow from the literature on anarchy and conflict when focusing on the process of exclusion in this paper. We interpret exclusion as a contest where the regional authority can invest in enforcement and the potential users can invest in appropriation. Both, investments in enforcement and appropriation determine the fraction of the spillover good for which exclusion is possible and a fraction where individuals will free ride.

The paper is complemented by an appendix (Appendix C) where we develop further insights into the economic mechanisms underlying the enforcement of user fees. We use a Tullock (1980) conflict and a Singh and Vives (1984) utility function that generates linear demand functions. Both functions are standard in the relevant fields of research (i.e. endogenous property rights ${ }^{11}$ and industrial organization). We parameterize the model with respect to a measure of relative superiority (inferiority) of investments in enforcement of user fees compared to investments in free riding. The resulting equilibrium utility levels turn out to be u-shaped in this parameter. The reason for this surprising finding is that the resource costs of enforcement are largest if enforcement and free-riding investments have similar productivities. Even though free riding is smaller than in a situation with less effective enforcement technology, the resource costs necessary to prevent additional free riding overcompensate any potential gains.

In addition it can be shown that two different enforcement regimes exist, depending on the relative effectiveness of enforcement. If enforcement is relatively difficult, free riding occurs in equilibrium. With increasing effectiveness of enforcement, free riding is continuously reduced and replaced by regular user-fee demand, this process is complemented by a steady increase in user fees. From a certain effectiveness of enforcement onwards, free riding can be completely deterred, and the consumption of the spillover good is exclusively user-fee financed. Interestingly, despite the fact that exclusion is perfect, user fees continue to rise if enforcement becomes more effective. The reason for this monotonicity even with perfect enforcement is that investments are set as to make users indifferent between paying user fees and investing in free riding. Hence, an increase in user fees increases the temptation for free riding, and regions take this effect into consideration. Given that the demand for spillover goods is usually decreasing in user fees, this shows that better enforcement technologies have an ambiguous effect of overall welfare. On the one hand, the resource costs

\footnotetext{
${ }^{9}$ For exemptions from this rule see Clotfelter (1977, 1978) and Laux-Mieselbach (1988).

${ }^{10}$ The literature on contests has recently been surveyed by Corchón (2007), Garfinkel and Skaperdas (2007), and Konrad (2009).

${ }^{11}$ An axiomatic foundation for the Tullock function for group contests can be found in Skaperdas (1996). An interpretation of the Tullock contest as a perfectly discriminatory noisy ranking contest can be found in $\mathrm{Fu}$ and $\mathrm{Lu}$ (2008).
} 
of enforcement go down. But on the other hand, total consumption of the spillover goods goes down as well, which is wasteful given their non-rival nature.

Theses findings complement the earlier literature on excludable non-rival goods. Brito and Oakland (1980) compare the provision of excludable non-rival goods by a monopolist that is restricted in its ability to discriminate prices between consumers. They find two types of inefficiencies compared to the first best. The monopolist will not provide the efficient quantity of the non-rival good, and he will exclude some of the consumers from the consumption of part of the good. Similar results are obtained by Fraser (1996) and Janeba and Swope (2001) who analyze user charges in different applications. Both papers get positive exclusion in equilibrium. The reason for their result is that the supplier of the public good is not allowed to discriminate prices between different users and is therefore restricted to Cournot-price setting. These inefficiencies are of course closely linked to the available pricing strategies. First-best efficiency would require individualized Lindahl prices. A market mechanism could implement those prices only by means of a monopoly with the ability to perfectly discriminate prices among users.

Our approach contributes to the economic theory of decentralization because the inefficiencies of decentralized user-fee policies are idiosyncratic to decentralization and could be avoided by either centralized tax financing or centralized user-fee setting. This does not mean that we have established an argument in favor of centralization because centralized authorities have their own idiosyncratic sources of inefficiencies. It is therefore a question of comparing the different types of transaction costs in order to determine the optimal hierarchical structure of governments.

The paper proceeds as follows. In Sect. 2 we present the formal model and the first-order conditions characterizing the equilibrium. This equilibrium and its welfare properties is analyzed in Sect. 3. Section 4 concludes. Proofs and the functional specification of the model can be found in Appendices A, B and C.

\section{The model}

Economy and governments The economy is divided into $n$ regions, $i=1, \ldots, n$. For simplicity we assume that every region is populated by a representative individual and has a local government that maximizes the utility of the regional resident. The government provides two goods. The first one is a local public good denoted by $g_{i}$. This good only benefits domestic citizens and exclusion is impossible. The second one is a non-rival good which has the physical quality to also benefit foreigners and for which exclusion is possible but costly. The quantity of the second good produced by region $i$ is denoted by $c_{i}$. For simplicity the production of the two goods is assumed to be linear in expenditures.

In order to finance its activities, region $i$ can levy user fees, $p_{i}=\left\{p_{i}^{1}, \ldots, p_{i}^{n}\right\}$ per unit of the spillover good $i$ demanded by domestic and foreign users, $c_{D}^{i}=$ $\left\{c_{1 D}^{i}, \ldots, c_{n D}^{i}\right\}$. Denote by $p^{i}=\left\{p_{1}^{i}, \ldots, p_{n}^{i}\right\}$ the user-fee vector faced by a resident of region $i$, and by $p=\left\{p_{1}, \ldots, p_{n}\right\}=\left\{p^{1}, \ldots, p^{n}\right\}$ the user-fee matrix. Analogously denote by $c_{i D}=\left\{c_{i D}^{1}, \ldots, c_{i D}^{n}\right\}$ the demand by resident $i$, and by 
$c_{D}=\left\{c_{1 D}, \ldots, c_{n D}\right\}=\left\{c_{D}^{1}, \ldots, c_{D}^{n}\right\}$ the demand matrix. Since exclusion of residents with respect to $g_{i}$ is impossible, no user fees can be levied on $g_{i}$.

As mentioned in the introduction, exclusion is a costly activity. If the government does not invest in exclusion, individuals will free ride on the supply of the public good $c_{i S}$, and the government cannot levy fees to finance its expenditures. In order to induce the payment, user fees have to be enforced. We assume that enforcement generates (endogenous) costs $e_{i}, e=\left\{e_{1}, \ldots, e_{n}\right\}$, for example the patrolling of police cars on the streets, the installation of toll booths, or simply the establishment of procedures that become necessary to administer the fees. We assume that investments improve enforcement of user fees against potential free riders from all regions. Depending on the investments for the enforcement of user fees, user fees themselves, and other technological constraints, the agents of the other regions can invest part of their resources $a_{i}=\left\{a_{i}^{1}, \ldots, a_{i}^{n}\right\}, a=\left\{a_{1}, \ldots, a_{n}\right\}$, (appropriation) to figure out ways to circumvent the enforcement measures by the other regions. For example the agents can use part of their time planning how to travel through the other region in order not to be detected, hiding from controls, etc. Contrary to defensive investments we assume that these investments are region specific.

The spillover good is non-rival in consumption between different users. However, each individual user has two potential "gateways" for its consumption. It can try to free-ride by investing $a_{i}^{j}$, or it can legally buy the spillover good by paying user fees. The total consumption of an individual is then the sum of free-riding and legal consumption. ${ }^{12}$ More formally, enforcement and appropriative investments influence exclusion as follows: given investments $e$ and $a, \pi_{i}^{j}=\pi_{i}^{j}\left(e_{j}, a_{i}^{j}\right)$ is the fraction of spillover good $j$ for which individual $i$ is successful in free riding, whereas government $j$ is successful in exclusion for the fraction $\left(1-\pi_{i}^{j}\left(e_{j}, a_{i}^{j}\right)\right)$ of the spillover good. Given the total supply of the spillover good $c_{j S}, c_{S}=\left\{c_{1 S}, \ldots, c_{n S}\right\}$, and the quantities demanded by domestic and foreign users, $c_{D}^{j}$, the quantity of spillover good $j$ actually consumed by individual $i$ is given by

$$
z_{i}^{j}=\pi_{i}^{j}\left(e_{j}, a_{i}^{j}\right) c_{j S}+c_{i D}^{j}
$$

Total consumption is therefore the sum of "free-rider" and "user-fee" consumption. Note that total consumption of spillover good $j$ by user $i$ cannot be larger than its total supply, $z_{i}^{j} \leq c_{j S}$, which yields the following constraint for user-fee consumption:

$$
\left(1-\pi_{i}^{j}\left(e_{j}, a_{i}^{j}\right)\right) c_{j S} \geq c_{i D}^{j}
$$

\footnotetext{
${ }^{12}$ A good example is public broadcasting in countries like Switzerland and Germany where "Rundfunkgebühren", a form of user fees, have to be paid as soon as a household owns a radio or TV set. Broadcasting is of course non-rival in consumption between different users. However, for every single user there exists a tradeoff between free-riding and paying user fees, and the total consumption will typically fall short of the total supply. In order to enforce user fees, both countries have established agencies with the permission to administer and collect the fees (Billag AG in Switzerland and Gebühreneinzugszenrale in Germany). They are empowered to carry out random-checks to ensure compliance, which makes free riding costly from the point of view of the individual user because he has to invest in precautionary measures to prevent being detected.
} 
We assume that $\pi_{i}^{j}\left(0, a_{i}^{j}\right)=1$, i.e. if the government does not invest in exclusion, households will be able to benefit from the entire supply of the good, irrespective of the quantity they buy $\left(c_{i D}^{j}\right)$. Analogously we assume that $\pi_{i}^{j}\left(e_{j}, 0\right)=0$ as long as $e_{j}>0$. Moreover,

$$
\begin{array}{ll}
\frac{\partial \pi_{i}^{j}}{\partial e_{j}} \leq 0, & \frac{\partial^{2} \pi_{i}^{j}}{\partial\left(e_{j}\right)^{2}} \geq 0, \quad \lim _{e_{j} \rightarrow \infty} \pi_{i}^{j}=0, \\
\frac{\partial \pi_{i}^{j}}{\partial a_{i}^{j}} \geq 0, & \frac{\partial^{2} \pi_{i}^{j}}{\partial\left(a_{i}^{j}\right)^{2}} \leq 0, \quad \lim _{a_{i}^{j} \rightarrow \infty} \pi_{i}^{j}=1,
\end{array}
$$

i.e. there is a declining "marginal effectiveness" of enforcement and appropriation. This exclusion technology resembles a contest-success function (CSF). The most widely used functional specification of such a function is given by the modified Tullock-CSF

$$
\pi\left(e_{j}, a_{i}^{j}\right)= \begin{cases}\frac{a_{i}^{j}}{a_{i}^{j}+\theta e_{j}}, & \exists a_{i}^{j}, e_{j}>0, \\ 1 & a_{i}^{j}=e_{j}=0,\end{cases}
$$

where $\theta$ measures the relative effectiveness of appropriation and defense. ${ }^{13}$ This function will be used in the examples throughout the paper.

The budget constraint of government $i$ is

$$
\sum_{j=1}^{n} p_{i}^{j} c_{j D}^{i}+t=c_{i S}+e_{i}+g_{i} .
$$

The left-hand side of the equation measures total revenues of the region levied from domestic and foreign users. To have a simplified exposition we assume that each government levies exogenous taxes $t \geq 0$ from the regional individual that can be used to finance part of the provision of the spillover and the regional public good. The righthand side of the equation measures total expenditures of the region. They include expenditures for the supply of the spillover good, expenditures for the enforcement of the user fees, and expenditures for the public good.

Individuals The representative individual in region $i$ derives utility from the consumption of a private good, $x_{i}$, from consumption of the local public good, $g_{i}$, and from the consumption of the spillover goods provided by the regions, $z_{i}^{j}$. W.1.o.g we assume that the price of the private good is normalized to one. The utility functions of the representative individuals are given by $u_{i}\left(x_{i}, z_{i}, g_{i}\right)$ which are assumed to be strictly quasi-concave, twice continuously differentiable and weakly separable between $g_{i}$ and the other arguments. Individuals $i, j$ are called identical if they have identical utility functions.

${ }^{13}$ See Grossman (2001) for further reference. 
The individual is endowed with a quantity $X$ of the numéraire good. Given user fees $p^{i}$, exclusion investments $e$, and the domestic and foreign supply of the spillover goods $c_{S}$, the budget constraint of a resident of region $i$ is

$$
x_{i}+\sum_{j=1}^{n} p_{j}^{i} c_{i D}^{j}+\sum_{j=1}^{n} a_{i}^{j}=X-t .
$$

Sequence of events We consider a two-stage game. At stage 1 every region noncooperatively determines its defensive activities, spillover-goods supply, user fees, and local public-goods supply, $T_{i}=\left\{e_{i}, c_{i}, p_{i}, g_{i}\right\}$, subject to the constraints that the government budget balances and that, for all $i$ and $j$, effective consumption of the spillover goods cannot exceed supply. i.e. $c_{j} \geq z_{i}^{j}$. At stage 2, individuals maximize their utility by the choice of demand of the private good, $x_{i}$, the demand of the spillover goods, $c_{i D}$, and appropriation, $a_{i}$. The game is solved by backwards induction.

Stage 2 An individual $i$ maximizes utility given (7), (1), (2), and non-negativity constraints for user-fee consumption and appropriation,

$$
\begin{array}{ll}
\max _{c_{i}, a_{i}, x_{i}} & u_{i}\left(x_{i}, z_{i}^{1}, \ldots, z_{i}^{n}, g_{i}\right) \\
\text { s.t. } \quad & x_{i}+\sum_{j=1}^{n} p_{j}^{i} c_{i D}^{j}+\sum_{j=1}^{n} a_{i}^{j}=X-t, \\
& \wedge z_{i}^{j}=\pi_{i}^{j}\left(e_{j}, a_{i}^{j}\right) c_{j S}+c_{i D}^{j}, \quad j=1, \ldots, n, \\
& \wedge\left(1-\pi_{i}^{j}\left(e_{j}, a_{i}^{j}\right)\right) c_{j} \geq c_{i D}^{j}, \quad j=1, \ldots, n, \\
& \wedge c_{i D}^{j} \geq 0 \wedge a_{i}^{j} \geq 0, \quad j=1, \ldots, n .
\end{array}
$$

Standard Kuhn-Tucker techniques can be used to derive the necessary conditions for the individual utility maximum, depending on the parameter values from the point of view of the individual. For future reference denote by $\lambda_{i}$ the Lagrange multiplier associated with budget constraint (7) and by $\rho_{i}^{j}, \varrho_{i}^{j}, \sigma_{i}^{j}$ the Lagrange multipliers (or complementary slackness parameters) associated with the supply constraint $\left(1-\pi_{i}^{j}\left(e_{j}, a_{i}^{j}\right)\right) c_{j S} \geq c_{i D}^{j}$ and non-negativity constraints $c_{i D}^{j} \geq 0, a_{i}^{j} \geq 0$. Throughout the paper we use the convention to call a constraint binding if the associated complementary slackness parameter is strictly positive. We call a constraint weakly binding if the associated complementary slackness parameter is positive or zero and the constraint holds with equality. We call a constraint not binding if it is not weakly binding.

Denote by $\operatorname{MRS}_{i}^{j}\left(z_{i}, x_{i}, g_{i}\right):=\frac{\partial u_{i}}{\partial z_{i}^{j}} / \frac{\partial u_{i}}{\partial x_{i}}$ the marginal rate of substitution between consumption of the spillover good and consumption of the rival good. $M R T_{i}^{j}\left(e_{j}, a_{i}^{j}, c_{j S}\right):=\frac{\partial \pi_{i}^{j}\left(e_{j}, a_{i}^{j}\right)}{\partial a_{i}^{j}} c_{j S} / 1$ is the marginal rate of transformation between the rival and spillover good using the channel of free riding. 
Table 1 Necessary conditions for the individual optimization problem

\begin{tabular}{|c|c|c|c|c|c|c|}
\hline & I & II & III & IV & V & VI \\
\hline$\left(1-\pi_{i}^{j}\right) c_{j S}-c_{i D}^{j}$ & $=0$ & $=0$ & $=0$ & $>0$ & $>0$ & $>0$ \\
\hline$a_{i}^{j}$ & $=0$ & $>0$ & $>0$ & $=0$ & $>0$ & $>0$ \\
\hline$c_{i D}^{j}$ & $>0$ & $>0$ & $=0$ & $>0$ & $>0$ & $=0$ \\
\hline$M R S_{i}^{j}$ & $\geq p_{j}^{i}$ & $\geq p_{j}^{i}$ & $\geq p_{j}^{i}$ & $=p_{j}^{i}$ & $=p_{j}^{i}$ & $=p_{j}^{i}$ \\
\hline$M R T_{i}^{j}$ & $\leq 1 / p_{j}^{i}$ & $=1 / p_{j}^{i}$ & $\geq 1 / p_{j}^{i}$ & $\leq 1 / p_{j}^{i}$ & $=1 / p_{j}^{i}$ & $\geq 1 / p_{j}^{i}$ \\
\hline
\end{tabular}

To gain intuition it is best to start with case $\mathrm{V}$ where both, free riding and legal demand of the spillover good are positive and the supply constraint is not binding. In this case, the marginal rate of substitution is equal to the relative price of the spillover good, $M R S_{i}^{j}=p_{j}^{i}$, and free-riding and legal consumption are balanced in a way as to equalize their marginal returns, $M R T_{i}^{j}=1 / p_{j}^{i}$. This is the standard case of a completely interior solution. All the other cases list potential corner solutions. They will become important in the analysis of optimal government policies later on.

Cases I-III comprise all situations where the supply constraint is weakly binding, $\left(1-\pi_{i}^{j}\right) c_{j S}-c_{i D}^{j}=0$, which implies that the individual would like to consume (weakly) more than what is actually in supply.

- In case I, the user fee is sufficiently small that the individual decides not to free ride. This case resembles the standard peak-load problem with binding capacity constraint.

- In case II, the individual mixes between free riding on and buying the spillover good. In this case, the decreasing effectiveness of appropriation implies that $a_{i}^{j}$ is uniquely determined for every $p_{j}^{i}$. This property will turn out to be important for the comparative-static properties of the model because the binding capacity constraint links demand and free-riding activities.

- Case III is the opposite to case I. Here, the user fee is so high and the enforcement activities are so low that the individual specializes in free riding.

Cases IV-VI, on the other hand, comprise all situations where the supply constraint is not binding, $\left(1-\pi_{i}^{j}\right) c_{j S}-c_{i D}^{j}>0$, total consumption of the spillover good falls short of its total supply. Case V has already been analyzed, so we can restrict attention to cases IV and VI now.

- In case IV, enforcement activities are sufficiently high to deter free riding (as in case I), but the user fee is too high to allow for a complete utilization of the spillover good.

- Case VI is again the opposite to case IV. Here, the user fee is so high and the enforcement activities are so low that the individual specializes in free riding but does not succeed to utilize the spillover good completely.

Cases I and IV share the property that the individual does not free ride. We will call this type of solution deterrence equilibrium in the following. For the example of a Tullock function, (5), the optimal investment in appropriation is $a_{i}^{j}=$ 
$\max \left[0, \sqrt{c_{j S} e_{j} p_{j}^{i} \theta}-e_{j} \theta\right]$, which implies that $a_{i}^{j}=0 \Leftrightarrow e_{j} \geq c_{j S} \cdot p_{j}^{i} / \theta$ : both, higher prices and a larger supply have to be accompanied by an increase in enforcement in order to induce the individual not to invest in appropriation. The opposite holds true for $\theta$ : larger values of $\theta$ make appropriation more difficult, which implies that enforcement can be reduced.

The solution to the household's maximization problem gives rise to demand and appropriation functions $c_{i D}^{j}\left(p^{i}, e, c_{S}, g_{i}\right), x_{i}\left(p^{i}, e, c_{S}, g_{i}\right), a_{i}^{j}\left(p^{i}, e, c_{S}, g_{i}\right)$, and an indirect-utility function $v_{i}\left(p^{i}, e, c_{S}, g_{i}\right)$.

Stage 1 The governments of the regions set their policies at stage 1 . We derive the equilibrium assuming that the governments set their policy instruments simultaneously and non-cooperatively. A decentralized Nash equilibrium is a vector $\left\{T_{i}\right\}_{i=1, \ldots, N}$ such that all regions maximize utility given the policy parameters of the other regions.

Given the budget constraint (6), the optimization problem of region $i$ is as follows:

$$
\begin{aligned}
& \max _{c_{i S}, e_{i}, p_{i}, g_{i}} v_{i}\left(p^{i}, e, c_{S}, g_{i}\right) \\
& \text { s.t. } \quad g_{i}+c_{i S}+e_{i}=\sum_{j=1}^{n} p_{i}^{j} c_{j D}^{i}\left(p^{j}, e, c_{S}, g_{j}\right)+t .
\end{aligned}
$$

Using the Envelope Theorem, the Kuhn-Tucker conditions of the associated Lagrangean with respect to the policy parameters are as follows $\left(\mu_{i}\right.$ denotes the Lagrange-multiplier associated with the budget constraint): ${ }^{14}$

$$
\begin{gathered}
e_{i}: \quad \frac{\partial u}{\partial z_{i}^{i}} \frac{\partial \pi_{i}^{i}}{\partial e_{i}} c_{i S}+\mu_{i}\left[\sum_{j=1}^{n} p_{i}^{j} \frac{\partial c_{j D}^{i}}{\partial e_{i}}-1\right]=0, \\
c_{i S}: \quad \frac{\partial u}{\partial z_{i}^{i}} \pi_{i}^{i}+\mu_{i}\left[\sum_{j=1}^{n} p_{i}^{j} \frac{\partial c_{j D}^{i}}{\partial c_{i S}}-1\right]=0, \\
p_{i}^{i}: \quad-\lambda_{i} c_{i D}^{i}+\mu_{i}\left[c_{i D}^{i}+p_{i}^{i} \frac{\partial c_{i D}^{i}}{\partial p_{i}^{i}}\right]=0, \\
p_{i}^{j}: \quad \mu_{i}\left[c_{j D}^{i}+p_{i}^{j} \frac{\partial c_{j D}^{i}}{\partial p_{i}^{j}}\right]=0, \quad j \neq i, \\
g_{i}: \quad \frac{\partial u}{\partial g_{i}}-\mu_{i}=0 .
\end{gathered}
$$

Some of the conditions are straightforward extensions of the two-region model with exogenous exclusion of free riding developed by Fuest and Kolmar (2007). We will very briefly discuss them here and focus instead on the novel aspect of multiple regions and the endogenous enforcement of user fees.

\footnotetext{
${ }^{14}$ The corresponding second-order conditions are assumed to be fulfilled.
} 


\section{Analysis of the decentralized Nash equilibrium}

In this section we analyze the decentralized policies and whether they are optimal for the country as a whole. If this is not the case, a potential for welfare-enhancing policy coordination arises. We restrict attention to user fees and exclusion investments. The welfare analysis is carried out under the assumption that user fees and exclusion investments marginally depart from the decentralized equilibrium and that investments in exclusion (the following case 3) and user fees (the following cases 1 and 2) are positive. Moreover, the government budget constraint is balanced by adjusting the supply of $g_{i}$. We denote by $\mathcal{L}_{i}(\cdot)$ the Lagrange function associated with optimization problem (9).

\subsection{User fees paid by domestic citizens}

We focus on user fee $p_{j}^{j}$ in the following. (12) implies that the optimal decentralized pricing rule with respect to $p_{j}^{j}$ is as follows:

$$
\frac{p_{j}^{j}}{c_{j D}^{j}} \frac{\partial c_{j D}^{j}}{\partial p_{j}^{j}}-\frac{\lambda_{j}-\mu_{j}}{\mu_{j}} \leq 0 .
$$

This condition implies that the user fee will be set as to equalize the demand elasticity with a measure for the marginal costs of public funds, $\left(\lambda_{j}-\mu_{j}\right) / \mu_{j} \leq 0$, in an interior solution. If the marginal costs of public funds are zero, $\lambda_{j}=\mu_{j}$, domestic user fees should therefore be equal to zero (Fuest and Kolmar 2007). We assume that the marginal costs of public funds are not equal to zero in the following.

In order to determine optimal user fees for the different scenarios described in I-VI, note first that case I can never be an equilibrium: if the supply constraint is binding, $\partial c_{j D}^{j} / \partial p_{j}^{j}=0$, and it is always profitable to increase the user fee. By the same token, scenarios III and VI can be ruled out because they imply no revenues from the user fee, which can always be avoided by lowering $p_{j}^{j}$ to almost zero.

Case IV resembles the model by Fuest and Kolmar (2007): without free riding, the effect of $p_{j}^{j}$ on $c_{j D}^{j}$ is only determined by $M R S_{j}^{j}=p_{j}^{j}$ and therefore exclusively driven by the structure of the utility function. If the spillover good is normal, the income effect cannot dominate the price effect, and demand is decreasing in the relevant user fee. In case V, however, a change in the user fee has an additional effect on free riding (appropriation effect). The appropriation effect is determined by optimality condition $\left(\partial \pi_{j}^{j} / \partial a_{j}^{j}\right) c_{j S}=1 / p_{j}^{j}$ which has to hold in addition to $M R S_{j}^{j}=p_{j}^{j}$. Given decreasing marginal effectiveness of appropriation, an increase in the user fee increases appropriation, and the appropriation effect is thereby ceteris paribus negative in the sense that it reduces demand.

In case II, the capacity constraint is binding and free riding occurs, which implies that $c_{j D}^{j}=\left(1-\pi_{j}^{j}\right) c_{j}$. Given that $\left(\partial \pi_{j}^{j} / \partial a_{j}^{j}\right) c_{j S}=1 / p_{j}^{j}$, the effect of a change in $p_{j}^{j}$ on $c_{j D}^{j}$ is $\partial c_{j D}^{j} / \partial a_{j}^{j}=-\left(\partial \pi_{j}^{j} / \partial a_{j}^{j}\right) c_{j S}<0$ because of the strict concavity of $\pi_{j}^{j}$ : the change in consumption is completely driven by the curvature of the exclusion technology. 
The differences to the case of exogenous and perfect exclusion are intuitive: A case with binding capacity constraints in the sense that $M R S_{j}^{j}>p_{j}^{j}$ can never occur in a model with perfect exclusion (see the above discussion of case I). In can occur in a model with endogenous exclusion because an increase in the user fee will be "retaliated" by an increase in free riding which reduces demand. The implied revenue effect can therefore be negative, and it is not clear that user fees will be driven up to the point where $M R S_{j}^{j}=p_{j}^{j}$. In a case with non-binding capacity constraint, higher fees also increase the pressure on free riding, and the optimal rule should take this into consideration by lowering fees. Hence, endogenous free riding has a dampening effect on domestic user fees.

One can use the Envelope Theorem to determine the effect of an increase in $p_{j}^{j}$ on region $i \neq j$ :

$$
\frac{d \mathcal{L}_{i}}{d p_{j}^{j}}=\frac{\partial \mathcal{L}_{i}}{\partial p_{j}^{j}}=\mu_{i} p_{i}^{j} \frac{\partial c_{j D}^{i}}{\partial p_{j}^{j}}
$$

for $j \neq i$. Hence, if a utilitarian criterion for the evaluation of a change in $d p_{j}^{j}$ is applied, we get

$$
\sum_{i \neq j} \frac{\partial \mathcal{L}^{i}}{\partial p_{j}^{j}}=\sum_{i \neq j} \mu_{i} p_{i}^{j} \frac{\partial c_{j D}^{i}}{\partial p_{j}^{j}}
$$

as the aggregate welfare effect of a change in $p_{j}^{j}$, evaluated at the decentralized equilibrium. It is useful to have the following definitions.

Definition 1 Spillover good $i$ is a substitute (complement) for spillover good $j$ for individual $j$ if $\partial c_{j D}^{i} / \partial p_{j}^{j}>(<) 0$.

Definition 2 Spillover goods $i \neq j$ are an average substitute (average complement) for spillover good $j$ for individual $j$ if $\sum_{i \neq j} \alpha_{i} \partial c_{j D}^{i} / \partial p_{j}^{j}>(<) 0, \alpha_{i} \in$ $[0,1], \sum_{i} \alpha_{i}=1$.

These definitions and the above condition can be used to show the following result. The proof can be found in Appendix A.

Result 1 Assume not all supply constraints for individual $j$ are binding, $\exists i \neq j$ : $\left(1-\pi_{j}^{i}\right) c_{i S}-c_{j D}^{i}>0$. (i) An increase in user fee $p_{j}^{j}$ increases (reduces) utilitarian welfare if and only if the foreign spillover-goods demand of region $j, c_{j D}^{i}, i \neq j$, is an average substitute (complement) for the domestic spillover good $c_{j D}^{j}$ with weights $\alpha_{i}=\mu_{i} p_{i}^{j} / \sum_{k \neq j} \mu_{k} p_{k}^{j}$. (ii) A change in user fee $p_{j}^{j}$ can never be a Pareto improvement for regions $i \neq j$ if there exist at least two regions $k, l \neq j$ such that $\operatorname{sgn}\left[\partial c_{j D}^{k} / \partial p_{j}^{j}\right] \neq \operatorname{sgn}\left[\partial c_{j D}^{l} / \partial p_{j}^{j}\right]$.

An increase in the user fee paid by domestic citizens creates a fiscal externality because demand for domestic and foreign spillover goods is interdependent. If the 
domestically supplied good is a substitute for all foreign goods, the increase in the fee for domestic users induces them to increase their demand for the foreign spillover good, which increases user-fee revenues and therefore raises welfare abroad. If the goods are all complements, however, the externality caused by an increase in user fees is negative because an increase in foreign prices is partly compensated by a decrease in domestic demand. This reduces foreign revenues, and foreign welfare is negatively affected. This effect is closely related to the so-called anti-commons problem. ${ }^{15}$ Up to this point our model extends the result in Fuest and Kolmar (2007) in a straightforward way.

In the case where not all other spillover goods are perceived as either complements or substitutes, the analysis departs from Fuest and Kolmar (2007). It is still possible to make a unanimous judgment based on utilitarian welfare ${ }^{16}$ that allows to aggregate the heterogeneous effects to some aggregate measure of net substitutability or net complementarity. However, any change in $p_{j}^{j}$ that makes at least one region better off makes some other region worse off. As a consequence, there is no way to achieve a Pareto-improvement relative to the decentralized equilibrium if at least two regions with opposing effects exist. For an example think of the road system of three regions. Region 1's roads are a substitute to region 2's roads and vice versa, and both are a complement to region 3's roads. ${ }^{17}$ In this case, an increase in tolls by region 1 is likely to increase demand in region 2 and (if region 1's and region 2's roads are not perfect substitutes) reduce demand in region 3.

The case of binding supply constraints follows readily:

Result 1a Assume all supply constraints for individual $j$ are binding, $\forall i \neq j$ : (1$\left.\pi_{i}^{j}\right) c_{j S}-c_{i D}^{j}=0$. An increase in user fee $p_{j}^{j}$ has no effect on individual or utilitarian welfare.

The intuition for this result is intuitive: If individual $j$ demands all foreign spillover goods up to the supply constraint, a marginal change in $p_{j}^{j}$ has neither an effect on this individuals' free-riding behavior (because the relative price of free riding on foreign spillover goods remains unchanged) nor on his demand. Hence, foreign user-fee revenues remain unchanged.

\subsection{Coordination of user fees paid by foreign citizens}

It is straightforward to check that optimal user fees with respect to non-residents are set as to maximize revenues (with the appropriate marginal costs depending on whether the supply constraint is binding or not, Fuest and Kolmar 2007). Given that this pricing rule must incorporate the endogeneity of free riding, the appropriation effect has to be included in the pricing rule. As before, the appropriation effect has a

\footnotetext{
${ }^{15}$ See Buchanan and Yoon (2000).

${ }^{16}$ And any other criterion of justice based on welfarism as well, of course.

${ }^{17}$ To be more specific think for example of freight at the port of Rotterdam that has to ultimately be shipped to Basel at the Swiss-French-German Border. The freight has to pass through the Netherlands but can then be either shipped via France or Germany.
} 
dampening effect on domestic user fees because higher user fees make larger investments in free riding profitable, which partly crowds out "legal" consumption $c_{i D}^{j}$.

With respect to overall welfare, the intuition given in the last paragraph should in principle also apply to the case of user fees paid by non-domestic users. However, the problem is different because contrary to the case of domestic user fees, the foreign direct-utility effect of an increase in user fees for non-residents is not internalized by the domestic government. The implied monopoly prices tend to be too high and are therefore a source of inefficiency of their own.

The welfare effect of a change in $p_{j}^{i}, j \neq i$ is qualitatively different for region $i$ and regions $k \neq i \neq j$ (we can again neglect the effect on $j$ because of the Envelope Theorem):

$$
\begin{aligned}
& \frac{d \mathcal{L}_{i}}{d p_{j}^{i}}=-\lambda_{i} c_{i D}^{j}+\mu_{i} p_{i}^{i} \frac{\partial c_{i D}^{i}}{\partial p_{j}^{i}}, \\
& \frac{d \mathcal{L}_{k}}{d p_{j}^{i}}=\mu_{k} p_{k}^{i} \frac{\partial c_{i D}^{k}}{\partial p_{j}^{i}} .
\end{aligned}
$$

The first term in (17) measures the direct, negative effect of monopoly pricing on the utility of region $i$. This effect is absent in region $k$, which is influenced only by the induced change in region $i$ 's demand structure. Hence, the direct effect reinforces the total effect if the goods are complements but mitigates it if the goods are substitutes. The utilitarian sum of welfare effects of a change in $p_{j}^{i}$ is then given as

$$
\sum_{k \neq j} \frac{d \mathcal{L}_{k}}{d p_{j}^{i}}=-\lambda_{i} c_{i D}^{j}+\sum_{k \neq j} \mu_{k} p_{k}^{i} \frac{\partial c_{i D}^{k}}{\partial p_{j}^{i}} .
$$

This leads to the following.

Result 2 (a) Assume not all supply constraints for individual $i$ are binding, $\exists k \neq j$ : $\left(1-\pi_{i}^{k}\right) c_{k S}-c_{i D}^{k}>0$. (i) An increase in user fee $p_{j}^{i}$ reduces utilitarian welfare if the spillover-goods demand by individual $i, c_{i D}^{k}, i \neq j, k \neq j$, is an average complement for the spillover-good demand $c_{i D}^{j}$. There is no clear-cut result for the case of average substitutes. (ii) A change in user fee $p_{j}^{i}$ need not be a Pareto improvement for regions $k \neq j$ if there exist at least two regions $k, l \neq j$ such that $\operatorname{sgn}\left[\partial c_{j D}^{k} / \partial p_{j}^{i}\right] \neq$ $\operatorname{sgn}\left[\partial c_{j D}^{l} / \partial p_{j}^{i}\right]$. It can never be a Pareto improvement for regions $k \neq j$ if there exist at least two regions $k, l \neq i, j$ such that $\operatorname{sgn}\left[\partial c_{j D}^{k} / \partial p_{j}^{i}\right] \neq \operatorname{sgn}\left[\partial c_{j D}^{l} / \partial p_{j}^{i}\right]$. (b) If all supply constraints for individual $i$ are binding, an increase in user fee $p_{j}^{j}$ reduces individual as well as utilitarian welfare.

The proof is analogue to that of Result 1 and is therefore omitted here. The result shows that the step from two to more than two regions is in fact crucial. Only if all regions perceive the spillover goods of all other regions qualitatively similar as either substitutes or complements or substitutes, the results by Fuest and Kolmar 
(2007) generalize to the $n$-region case. If regions can qualitatively differ in their perceptions of the other regions' spillover goods there is no room for user-fee changes, which makes these regions unambiguously better off. In these cases, a utilitarian welfare criterion replaces the substitutes-complements rule by a rule that focusses on a concept of average substitute/complement. In the general case with binding capacity constraints and appropriation in equilibrium, the additional appropriation effect also works along the same lines as before.

\subsection{Coordination of investments to prevent free riding}

What is the scope for welfare enhancing coordination of enforcement policies? To understand the strategic effects resulting from this investment decision, we analyze the effect of a change in exclusion investments $e_{j}$ on welfare in region $i$ :

$$
\frac{d \mathcal{L}_{i}}{d e_{j}}=\frac{\partial u_{i}}{\partial z_{i}^{j}} \frac{\partial \pi_{i}^{j}}{\partial e_{j}}+\sum_{k=1}^{n} \mu_{i} p_{i}^{k} \frac{\partial c_{k D}^{i}}{\partial e_{j}}
$$

for $i \neq j$. The first term is unambiguously negative in cases II and V because the increase in enforcement reduces free-rider consumption. It is zero in case IV where free riding from $i$ has been successfully prevented by high enough enforcement levels. The second effect is a budget effect because of the implied change in the demand structure. In general, no predictions about the sign of this effect can be made.

To fix ideas assume that utility is linear in the consumption of the private good for all individuals. In this case, an increase in $e_{j}$ unambiguously increases demands $c_{k D}^{j}$ for all $k$. The budget effect for region $i$ results if these demand changes by region $k$ affect the demand for spillover good $i . \partial c_{k D}^{i} / \partial e_{j}$ measures the change in demand for spillover good $i$ by resident $k$ induced by a change in region $j$ 's enforcement. Theoretically, this effect can be positive as well as negative. $k$ 's demand for good $i$ tends to go up if $c_{k D}^{j}$ and $c_{k D}^{i}$ are complements and tends to go down if they are substitutes. Hence, the direct negative effect on $i$ 's utility is reinforced if the spillover goods are substitutes. In the case that they are complements, however, the budget effect works counter to the direct effect such that no prediction about the welfare consequences in $i$ can be made.

It is instructive to start with an analysis of the two-region case for an analysis of the efficiency of the decentralized equilibrium.

Result 3 Assume there are two regions, $i$ and $j$, and domestic users are not excluded from the use of the spillover good, $p_{i}^{i}=p_{j}^{j}=0$, or user fees are perfectly enforced against domestic users. Then, exclusion investments are inefficiently high if free riding occurs in a decentralized equilibrium. If, on the other hand, there is no free riding in the decentralized equilibrium, exclusion is efficient.

The result gives a nice example for the intuitive case that the ability of a region to raise revenues from non-residents creates an incentive to invest more in exclusion technologies than socially optimal because the region does not internalize the negative externality that comes with reduced free riding. However, the result also points 
to the limitations of this intuition. If user fees are set as to allow some degree of free riding, an increase in enforcement in $j$ can increase the demand of region $i$ 's spillover good. If the latter effect is sufficiently strong, region $i$ can in fact profit from increased enforcement in region $j$.

It is impossible to derive general results for $p_{i}^{i}>0, p_{j}^{j}>0$ because an increase in $e_{j}$ induces complex spillover effects that lack a general structure. A change in $e_{j}$ will have an impact on the demands for spillover good $j$, which in turn influences the demands for spillover good $i$. The sign of the former effect is ambiguous in general. In addition, the induced effects on the demand of spillover good $i$ depend on whether both goods are substitutes or complements. For example assume that an increase in enforcement in $j$ increases domestic demand, and that foreign demand is a substitute (complement). Then, an increase in $e_{j}$ has a negative (positive) effect on region $i$ 's budget constraint. Therefore, no general conclusion can be drawn.

It follows from the above discussion that it cannot be expected to get general results for the case of more than two regions. The aggregate (utilitarian) effect of a change in $e_{j}$ for a utilitarian welfare measure is

$$
\sum_{i \neq j} \frac{d \mathcal{L}_{i}}{d e_{j}}=\sum_{i \neq j} \frac{\partial u_{i}}{\partial z_{i}^{j}} \frac{\partial \pi_{i}^{j}}{\partial e_{j}}+\sum_{i \neq j}\left(\sum_{k=1}^{n} \mu_{i} p_{i}^{k} \frac{\partial c_{k D}^{i}}{\partial e_{j}}\right) .
$$

The general case does not even have a regular structure if one assumes that domestic users are not charged for the use of spillover goods. An increase in $e_{j}$ will in general have an effect of individual $k$ 's demand for spillover good $i$. These cross effects (that are absent in the case of only two regions) create budget effects in region $i$ that do not allow any general conclusion.

\section{Conclusions}

This paper has extended the framework for thinking about the decentralized incentives to set user fees for the financing of interregional spillover goods that has been developed by Fuest and Kolmar (2007). It extends the analysis by allowing for $n$ regions and by interpreting the process of exclusion as an economic activity where potential free riders and regional authorities invest resources to be able to free ride or to prevent free riding. Not surprisingly, decentralized policies cause a number of externalities that lead to the strategic setting of fees. Hence, economic integration is likely to cause problems for price mechanisms which are similar to those faced by tax mechanisms. A shift towards user-fee financing of publicly provided goods is therefore no way out of the problem of tax competition. The extension to more than two regions reveals that policy coordination does not lead to Pareto-improvements if regions are heterogeneous with respect to their pattern of complementarity/substitutability between spillover goods. However, a clear-cut welfare comparison between decentralized and coordinated policies is possible if one is willing to accept a utilitarian criterion. In this case, an index of average substitutability between spillover goods turns out to be decisive for the evaluation of decentralized user fees. 
In the appendix we further explore the functioning of the exclusion mechanism. For the case of two regions, decentralized investments in exclusion are too high if only non-domestic users are charged for their use of spillover goods. Unfortunately it has been impossible to show robust results for the general case of $n$ regions and/or user fees for domestic users. If exclusion is an economic activity, our analysis further reveals that the total costs of exclusion are hump shaped in some parameter that represents the relative effectiveness of exclusion compared to free-riding investments. This result shows that better enforcement technologies need not improve economic welfare, on the contrary, they may encourage both sides, potential free riders as well as regional authorities, to engage more heavily in the contest for the use of spillover goods.

\section{Appendix A: Proof of Result 1}

Proof The welfare effect of a change in $p_{j}^{j}$ for region $i$ is given by

$$
\mu_{i} p_{i}^{j} \frac{\partial c_{j D}^{i}}{\partial p_{j}^{j}},
$$

which measures the additional utility of an $i$-resident resulting from a change in userfee revenues collected from individual $j\left(\mu_{i}\right.$ is the marginal utility of an additional unit of government revenue in region $i$ ).

(i) Assume there exists a region $i$ such that $\partial c_{j D}^{i} / \partial p_{j}^{j} \neq 0 \forall i \neq j$. Then,

$$
\sum_{i \neq j} \mu_{i} p_{i}^{j} \frac{\partial c_{j D}^{i}}{\partial p_{j}^{j}}
$$

is the sum of additional utilities for all regions $i \neq j$, which implies that utilitarian welfare increases (decreases) in $p_{j}^{j}$ if (A.2) is positive (negative). Define $\alpha_{i}=\mu_{i} p_{i}^{j} / \sum_{k \neq j} \mu_{k} p_{k}^{j}$ with $\alpha_{i} \in[0,1], \sum_{i \neq j} \alpha_{i}=1$. It follows immediately from (A.2) that utilitarian welfare increases (decreases) in $p_{j}^{j}$ iff

$$
\sum_{i \neq j} \alpha_{i} \frac{\partial c_{j D}^{i}}{\partial p_{j}^{j}}>(<) 0
$$

which are the definitions for average substitutes and average complements.

(ii) Given that $\mu_{i} p_{i}^{j}>0 \forall i \neq j$ (remember that $p_{i}^{j}=0$ can never be optimal for a region $i$ ) the direction of the regional welfare effect is determined by the substitutability or complementarity of this regions' spillover good for user $j$. If $\exists i, k$ such that $\partial c_{j D}^{i} / \partial p_{j}^{j}>0, \partial c_{j D}^{k} / \partial p_{j}^{j}<0$, region $i$ 's welfare goes up whereas region $k$ 's welfare goes down, hence a change in user fees can never be a Pareto-improvement.

Finally, if the supply constraint is binding in region $i,\left(1-\pi_{i}^{j}\right) c_{i S}-c_{j D}^{i}=$ $0 \wedge \rho_{j}^{i}>0$, it must be that $\partial c_{j D}^{i} / \partial p_{j}^{j}=0$ irrespective of whether spillover goods 
$j$ and $i$ a substitutes or complements for individual $j$. Hence, at least one supply constraint has not to be binding to create positive or negative externalities between regions.

\section{Appendix B: Proof of Result 3}

Proof With only two regions, (20) measures the aggregate externality imposed by region $j$ and simplifies to

$$
\frac{d \mathcal{L}_{i}}{d e_{j}}=\frac{\partial u_{i}}{\partial z_{i}^{j}} \frac{\partial \pi_{i}^{j}}{\partial e_{j}}+\mu_{i} p_{i}^{i} \frac{\partial c_{i D}^{i}}{\partial e_{j}}+\mu_{i} p_{i}^{j} \frac{\partial c_{j D}^{i}}{\partial e_{j}} .
$$

(i) Assume that domestic users consume the spillover good for free, $p_{i}^{i}=p_{j}^{j}=0$, which implies that the second term on the right-hand side of the above equation is equal to zero. Furthermore, without exclusion of domestic users, a change in $e_{j}$ leaves the budget constraint of a $j$-resident unchanged. It follows directly that $\partial c_{j D}^{i} / \partial e_{j}=0$. Hence, only the direct negative effect (first term on the right-hand side) remains. (ii) Assume that enforcement is perfect. In this case, an increase in $e_{j}$ has no direct negative effect on $i$ 's utility, and it cannot influence the demand of spillover goods (which has been determined under conditions of perfect enforcement anyway).

\section{Appendix C: The role of the exclusion technology on the decentralized equilibrium}

In this appendix we further explore the economic mechanisms underlying the enforcement of user fees using a functional specification of the above model. The fact that regions are in a position of monopolistic competition with respect to the spillover goods creates a problem for any functional specification of the model because standard utility functions that generate iso-elastic demand functions yield no interior solution for the monopoly problem. Basically one finds two classes of utility functions that are used for a micro-foundation of Marshallian demand functions that yield interior solutions for markets with imperfect competition, a generalized StoneGeary form (Yin 2001) and a class of linear quadratic functions (Singh and Vives 1984). Only the latter class generates interior solutions for the boundary case of zero marginal costs of providing a good, which is essential to the problem at hand because of the non-rival nature of the spillover good. We have therefore used a special case of the function introduced by Singh and Vives (1984). Assume that there are two regions $i=1,2$. The representative individual in region $i$ has the following utility function:

$$
u_{i}\left(x_{i}, c_{i}^{i}, c_{i}^{j}, g_{i}\right)=x_{i}+c_{i}^{i}-\frac{1}{2}\left(c_{i}^{i}\right)^{2}+c_{i}^{j}-\frac{1}{2}\left(c_{i}^{j}\right)^{2}+g_{i} .
$$

Note that this functional form implies that the individuals have a satiation point for the spillover goods at $c_{i}^{i}=c_{i}^{j}=1$. We employ the assumption-standard in the literature 
on Industrial Organization-that the marginal costs of producing the spillover goods are equal to zero. ${ }^{18}$ This convention allows it to focus on the functioning of the priceand exclusion mechanisms.

With marginal costs of zero, the Pareto-efficient quantities of the spillover goods are equal to $c_{i S}=1$, their satiation levels. Note further that this quantity will also provided in the decentralized game: the voluntary-contributions game does not lead to underprovision of the spillover goods. However, the decentralized equilibrium may lead to inefficient investments in free riding and exclusion as well as to inefficient exclusion in order to maximize revenues from non-resident users. We make the additional assumption that domestic residents are not charged for their consumption of the non-rival good, $p_{1}^{1}=p_{2}^{2}=0$. Exclusion is only targeted against foreign users to involve them in the financing of the non-rival good.

The exclusion technology is given by a standard Tullock contest-success function given in (5). Note that the parameter $\theta$ determines the relative effectivity of investments in exclusion compared to investments in free riding. Larger values of $\theta$, therefore, imply a more effective exclusion technology, and different empirical applications may differ with respect to the ability to enforce compliance. The enforcement of user fees in education is, for example, relatively easy, implying a relatively large value of $\theta$, whereas the enforcement of user fees for roads is considerably more difficult, implying a smaller value of $\theta$. We will explore the consequences of different values of $\theta$ in detail in the following. We say that the exclusion technology is balanced if $\theta$ is in an interval around 1 , and we say that the exclusion technology is unbalanced if $\theta$ converges either to 0 (favoring free riding) or $\infty$ (favoring enforcement).

Assuming $c_{i}=1$, the solution of the individual maximization problem at stage 2 gives rise to the following Marshallian demand functions: ${ }^{19}$

$$
\begin{aligned}
c_{i D}^{j}\left(e_{j}, p_{i}^{j}, \theta\right) & =\max \left[0, \sqrt{e_{j} \theta / p_{i}^{j}}-p_{i}^{j}\right], \\
a_{i}^{j}\left(e_{j}, p_{i}^{j}, \theta\right) & =\max \left[0, \sqrt{e_{j} \theta p_{i}^{j}}-\theta e_{j}\right] .
\end{aligned}
$$

A short inspection reveals that $a_{i}^{j}\left(e_{j}, p_{i}^{j}, \theta\right) \geq 0 \Leftrightarrow e_{j} \leq p_{i}^{j} / \theta$ and $c_{i D}^{j}\left(e_{j}, p_{i}^{j}, \theta\right) \geq$ $0 \Leftrightarrow e_{j} \geq\left(p_{i}^{j}\right)^{3} / \theta$, which implies that there are four different regimes:

- $c_{i D}^{j}\left(e_{j}, p_{i}^{j}, \theta\right)>0, a_{i}^{j}\left(e_{j}, p_{i}^{j}, \theta\right)>0$ : the individual invests in appropriation but at the same time buys part of the good. This situation is likely to occur if appropriation is relatively easy ( $\theta$ is small) and the price of the good is low.

- $c_{i D}^{j}\left(e_{j}, p_{i}^{j}, \theta\right)>0, a_{i}^{j}\left(e_{j}, p_{i}^{j}, \theta\right)=0$ : The individual exclusively buys the good. This situation is likely to occur if appropriation is relatively difficult ( $\theta$ is large) and the price of the good is low.

\footnotetext{
${ }^{18}$ One has to distinguish between the production costs of a given quantity of the spillover good that may be positive or not, and the costs of an additional user that are necessarily equal to zero if the good in non-rival in consumption.

${ }^{19}$ The calculations of this model have been carried out using the software package Mathematica 8.0. The source code can be received from the authors upon request.
} 
- $c_{i D}^{j}\left(e_{j}, p_{i}^{j}, \theta\right)=0, a_{i}^{j}\left(e_{j}, p_{i}^{j}, \theta\right)>0$ : the individual invests in appropriation and completely free rides. This situation is likely to occur if appropriation is relatively easy $(\theta$ is small) and the price of the good is high.

- $c_{i D}^{j}\left(e_{j}, p_{i}^{j}, \theta\right)=0, a_{i}^{j}\left(e_{j}, p_{i}^{j}, \theta\right)=0$ : the individual completely free rides without investing in appropriation. This situation can occur if (i) exclusion is not possible ( $e_{j}=0$ because $\theta=0$ ) or because the individual is deterred from appropriation and the price is so high that it is not willing to buy the good either.

Note that scenarios 3 and 4 can never be rational from the point of view of the other region as long as $\theta>0$ (the good is not purely public, exclusion is possible in principle). The only reason to invest in exclusion is to raise revenue from user fees, which implies that $c_{i D}^{j}\left(e_{j}, p_{i}^{j}, \theta\right)$ has to be positive. This can always be accomplished by lowering $p_{i}^{j}$. We can therefore restrict attention to scenarios 1 and 2 . In scenario 1 , free-riding and user-fee payment take place at the same time, whereas free riding is deterred in scenario 2 .

Given the above analysis, the indirect-utility function is given by

$$
\begin{aligned}
& v_{i}^{j}\left(e_{j}, p_{i}^{j}, \theta\right) \\
& \quad= \begin{cases}2+\frac{\left(p_{i}^{j}\right)^{2}}{2}-\left(p_{j}^{i}\right)^{2}-2 \sqrt{e_{j} p_{i}^{j} \theta}+\sqrt{e_{i} p_{j}^{i} \theta}+e_{j} \theta-e_{i}, & c_{i D}^{j}>0, a_{i}^{j}>0, \\
2+\frac{\left(p_{i}^{j}\right)^{2}}{2}-\left(p_{j}^{i}\right)^{2}-p_{i}^{j}+p_{j}^{i} \frac{\theta-1}{\theta} & c_{i D}^{j}>0, a_{i}^{j}=0 .\end{cases}
\end{aligned}
$$

In order to determine the optimal $\left\{e_{i}, p_{i}^{j}\right\}$-pairs we start with the analysis of deterrence. In this case, it is straightforward to derive from (C.4) that the optimal user fee from the point of view of region $i$ is independent of the policies of region $j$ and given by $p_{i}^{j}=(1-1 / \theta) / 2$, and the associated demand is $c_{i D}^{j}(\theta)=(1+1 / \theta) / 2$. The price is (weakly) positive and the demand does not exceed supply if $\theta>1$. This information can be used to calculate indirect-utility functions in case of deterrence $(D)$ :

$$
w_{i D}^{j}\left(\theta, p_{i}^{j}, e_{j}\right)=1.75+\frac{\left(p_{i}^{j}\right)^{2}}{2}+\frac{1}{4 \theta^{2}}-2 \sqrt{e_{j} p_{i}^{j} \theta}+\frac{\theta-1}{2 \theta}+e_{j} \theta .
$$

In case of an interior solution with coexisting free-riding and user-fee payment, it follows from (C.4) that the optimal policies are again independent and given by $e_{i}=$ $\theta^{2} / 32$ and $p_{i}^{j}=\theta / 8$. The associated demand for the spillover good and appropriative investments are given by

$$
c_{i D}^{j}(\theta)=\frac{3 \theta}{8}, \quad a_{i}^{j}(\theta)=\frac{\theta^{3}}{32} .
$$

This implies that a fraction $1-\theta / 2$ of the non-rival good is appropriated. Total consumption of the spillover good is then $1-\theta / 8<1$, which implies that total demand never exceeds supply. As before, this information can be used to calculate indirect- 


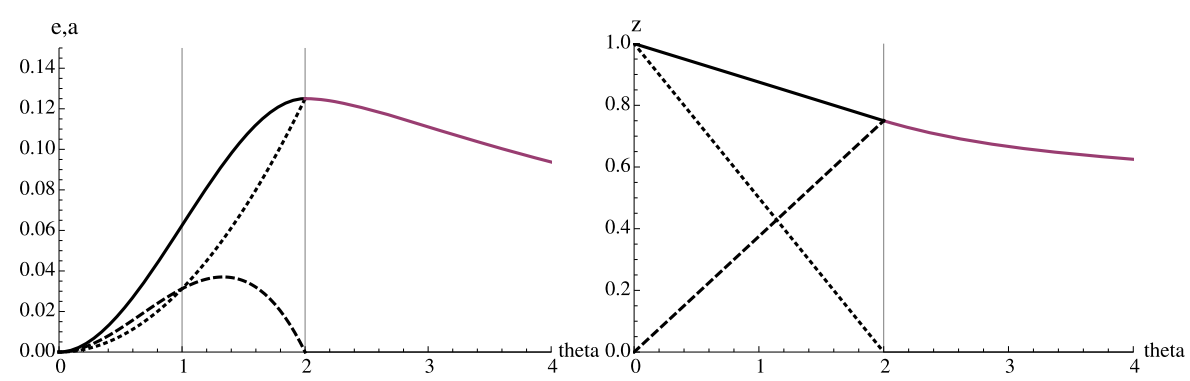

Fig. 1 Investments in exclusion and free riding (left panel) and consumption of the other region's spillover good (right panel) as functions of $\theta$

utility functions in case of free riding $(F)$ :

$$
w_{i F}^{j}\left(\theta, p_{i}^{j}, e_{j}\right)=2+\frac{\left(p_{i}^{j}\right)^{2}}{2}+e_{j} \theta-2 \sqrt{e_{j} p_{i}^{j} \theta}+\frac{\theta^{2}}{64} .
$$

Comparing (C.7) and (C.5) reveals that it is optimal to allow for free riding if $\theta<2$ and to deter free riding if $\theta>2$. The following figures summarize the results of the model.

The left panel of Fig. 1 displays investments in exclusion $\left(e_{i}\right)$ (dotted, increasing line) and free riding $\left(a_{i}\right)$ (dashed, inversely u-shaped line) as well as aggregate investments $\left(e_{i}+a_{i}\right)$ (solid line). For $\theta<2$, appropriation and defense coexist, whereas aggregate investments are equal to investments in exclusion for $\theta>2$ (deterrence equilibrium).

The right panel of Fig. 1 displays free-riding consumption $\left(\pi_{i}^{j} c_{i}\right)$ (dotted, decreasing line), consumption with payment of user fees $\left(c_{i D}^{j}\right)$ (dashed, increasing line up to $\theta=2$ ), and aggregate consumption $\left(\pi_{i}^{j} c_{i S}+c_{i D}^{j}\right)$ (solid, decreasing line). For $\theta<2$ there is free riding on part of the spillover good, whereas no free riding occurs if $\theta>2$. For $\theta \rightarrow 0$ exclusion is almost impossible, which implies that the total resource costs of exclusion and free riding are approximately zero: given that exclusion is virtually impossible, the individuals can free ride for (almost) free. As a consequence, total consumption is almost exclusively composed of free-riding consumption, and the socially efficient amount of the spillover good is consumed.

If $\theta$ gets larger (but stays smaller than 2), exclusion becomes increasingly easier, which implies that each region starts investing in exclusion, which is first retaliated by an increase in free-rider investments. As a consequence, the total resource costs of exclusion go up. If $\theta=1$ neither exclusion nor appropriation has a relative advantage, which implies that both investments are identical. For larger values of $\theta$, appropriation becomes more and more difficult, implying that the increase in exclusion investments eventually force free riding investments to go down until at $\theta=2$ free riding is completely eliminated. Note that from the point of view of total resource costs that are necessary to eliminate free riding, the economy pays a high price: the sum of exclusion and free riding investments are maximized at $\theta=2$. For larger values of $\theta$, the total resource costs of exclusion go down again because it is getting 

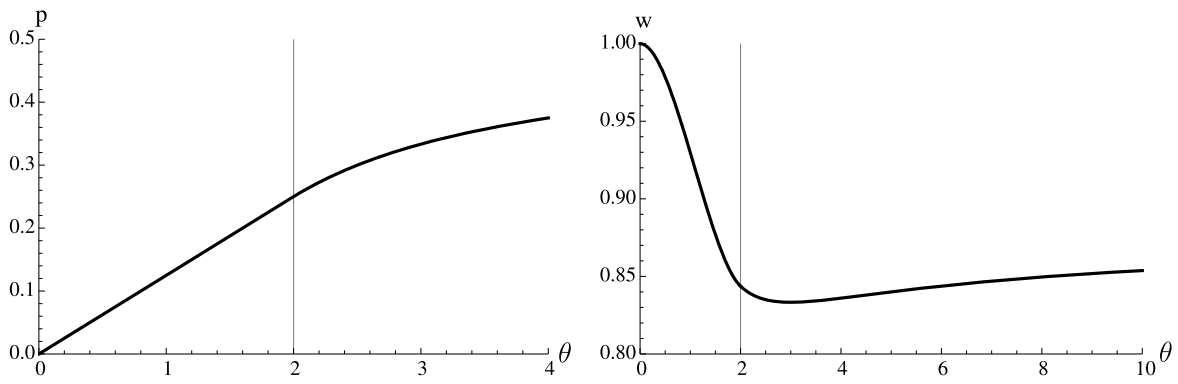

Fig. 2 User fees (left panel) and regional welfare (right panel) as a function of $\theta$

increasingly easier to prevent free riding. In the limit for $\theta \rightarrow \infty$, even the tiniest investment in exclusion completely prevents free riding.

With respect to the composition of consumption of the spillover good it follows from the right panel of Fig. 2 that for $\theta<2$ free riding is increasingly replaced by user-fee financed consumption until for $\theta \geq 2$ user fees are paid for $100 \%$ of consumption. A second observation is that total consumption falls monotonically in $\theta$, which implies that the inefficiency due to the non-utilization of the non-rival goods is increasing in $\theta$. The left panel of Fig. 2 shows that this is a consequence of the steady increase in user fees that comes along with the easier prevention of free riding. Interestingly, user fees are increasing in $\theta$ even if free riding is completely deterred $(\theta>2)$. The reason follows from the logic of marginal conditions: investments in the enforcement of user fees are set as to make the potential free rider just indifferent between paying user fees and investing in free riding. As a consequence, higher user fees increase the temptation to start free riding. This temptation is falling in $\theta$, implying that higher user fees can be sustained.

User fees have the potential to help internalizing the spillovers of regionally provided non-rival goods, but regions use them primarily as a source to raise revenues. This view is further confirmed if one has a look at the associated welfare levels. In our example the former motive is completely absent. The right panel of Fig. 2 shows the regional (indirect) utility levels in the Nash equilibrium. Two properties spring to mind:

1. Comparing the extreme cases $\lim _{\theta \rightarrow 0} w_{i F}^{j}(\theta)=1$ and $\lim _{\theta \rightarrow \infty} w_{i D}^{j}(\theta)=0.875$ reveals that the use of the price mechanism has welfare costs even if free riding can be prevented for (almost) free. This finding is of course a consequence of the property that regions voluntarily provide the efficient quantity of the spillover good. If this would not be the case, free riding would induce additional welfare costs because of the (partial) non-internalization of the interregional spillovers. In this case, user fees (partly) internalize these spillovers and help to bring the economy closer to efficiency. However, even in this case the general tradeoff highlighted by our result remains: the decentralized setting of user fees cannot be expected to be efficient because of the dominant interest in maximizing revenues from non-resident use.

2. The u-shape of the graph results from the fact that the resource costs of preventing free riding are large if the exclusion technology is relatively balanced. This 
finding reveals a general property of economic conflicts where individual success depends on relative instead of absolute performance. Given that the prevention of free riding with is a special type of property-rights enforcement has the character of a conflict our results do not hinge on the specific functional forms employed but reveal a general pattern. ${ }^{20}$ Improvements in the technology of enforcement may worsen overall efficiency. This effect occurs if (i) enforcement is relatively difficult and (ii) improvements are sufficiently limited.

\section{References}

Brito, D. L., \& Oakland, W. H. (1980). On the monopolistic provision of excludable public goods. American Economic Review, 70, 691-704.

Buchanan, J. M., \& Yoon, Y. L. (2000). Symmetric tragedies: commons and anticommons. The Journal of Law \& Economics, 43, 1-13.

Clotfelter, C. T. (1977). Public services, private substitutes, and the demand for protection against crime. American Economic Review, 67, 867-877.

Clotfelter, C. T. (1978). Private security and the public safety. Journal of Urban Economics, 5, 388-402.

Corchón, L. C. (2007). The theory of contests: a survey. Review of Economic Design, 11, 69-100.

Fraser, C. D. (1996). On the provision of excludable public goods. Journal of Public Economics, 60, 111130.

Fu, Q., \& Lu, J. (2008). Micro foundations of multi-prize lottery contests: a perspective of noisy performance ranking. Social Choice and Welfare (forthcoming)

Fuest, C., \& Kolmar, M. (2007). A theory of user-fee competition. Journal of Public Economics, 91, 497509.

Garfinkel, M. R., \& Skaperdas, S. (2007). Economics of conflict: an overview, handbook of defense economics. Amsterdam: Elsevier.

Grossman, H. (2001). The creation of effective property rights. American Economic Review, 91, 347-352.

Janeba, E., \& Swope, K. J. (2001). Taxes or fees? The political economy of providing excludable public goods. Journal of Public Economic Theory, 7, 405-426.

Konrad, K. (2009). Strategy and dynamics in contests. Oxford: Oxford University Press.

Laux-Mieselbach, W. (1988). Impossibility of exclusion and characteristics of public goods. Journal of Public Economics, 36, 127-137.

Oates, W. (1999). An essay on fiscal federalism. Journal of Economic Literature, 37, 1120-1149.

Polinsky, A. M., \& Shavell, S. (2000). The economic theory of public enforcement of law. Journal of Economic Literature, 38, 45-76.

Singh, \& Vives, X. (1984). Price and quantity competition in a differentiated duopoly. The Rand Journal of Economics, 15, 546-554.

Skaperdas, S. (1996). Contest success functions. Economic Theory, 7, 283-290.

Tiebout, C. (1956). A pure theory of local expenditures. Journal of Political Economy, 64(5), 416-424.

Tullock, G. (1980). Rent seeking as a negative-sum game. In J. M. Buchanan \& G. Tullock (Eds.), Toward a theory of the rent seeking society (pp. 16-36). College Station: Texas A\&M University Press.

Yin, X. (2001). A tractable alternative to Cobb-Douglas utility for imperfect competition. Australian Economic Papers, 40, 14-21.

${ }^{20}$ See Garfinkel and Skaperdas (2007) for a comprehensive discussion. 